\title{
A malignant lymphoma growing inside a cardiac mixoma: a case report
}

\author{
Sergio Pirola ${ }^{1}$, Giorgio Mastroiacovo ${ }^{2}$, Stefano Fiori $^{3}$, Fausto Maffini ${ }^{3}$, Giulia Mostardini ${ }^{1}$, \\ and Gianluca Polvani ${ }^{4}$ \\ ${ }^{1}$ Centro Cardiologico Monzino Istituto di Ricovero e Cura a Carattere Scientifico \\ ${ }^{2}$ Centro Cardiologico Monzino IRCCS \\ ${ }^{3}$ Istituto Europeo di Oncologia \\ ${ }^{4}$ centro cardiologico monzino
}

January 27, 2021

\begin{abstract}
Background: lymphomas arising in cardiac myxomas represent a particularly rare pathology, with only few cases reported in the literature. Case presentation: we report a completely exeresis of malignant lymphoma arising in a cardiac myxoma in a 44 years-old female patient. The myxoma presented like a floating mass within the left atrium with a maximum diameter of 3.5 $\mathrm{cm}$. The clinical post-operative period was uneventful and the patient was dismissed on sixth post-operative day. Conclusions: This case reinforces the concept of a radical exeresis of cardiac neoplasms
\end{abstract}

A malignant lymphoma growing inside a cardiac mixoma: a case report

Sergio Pirola $\mathrm{MD}^{1 *}$, Giorgio Mastroiacovo $\mathrm{MD}^{1,2 *}$, Stefano Fiori $\mathrm{MD}^{3}$, Fausto Maffini $\mathrm{MD}^{4}$, Giulia Mostardini RT ${ }^{1}$ and Gianluca Polvani $\mathrm{MD}^{1,2}$

*These authors equally contributed to this manuscript

Corresponding Author: Sergio Pirola MD, IRCCS Centro Cardiologico Monzino, street Parea 4 - 20138 Milan, Italy, Tel. +39 0258002329, E-mail: sergio.pirola@ccfm.it.

\section{Abstract}

Background: lymphomas arising in cardiac myxomas represent a particularly rare pathology, with only few cases reported in the literature.

Case presentation: we report a completely exeresis of malignant lymphoma arising in a cardiac myxoma in a 44 years-old female patient. The myxoma presented like a floating mass within the left atrium with a maximum diameter of $3.5 \mathrm{~cm}$. The clinical post-operative period was uneventful and the patient was dismissed on sixth post-operative day.

Conclusions: This case reinforces the concept of a radical exeresis of cardiac neoplasms.

Keywords: cardiac myxoma, malignant lymphoma, Epstein-Barr virus.

\section{Background}

Cardiac myxomas account for the majority of cardiac tumours (50\%) and mainly affect middle-aged females [1]. Primary cardiac lymphoma is a very rare neoplasm that accounts for $2 \%$ of all primary cardiac tumours 
[2]. Lymphomas growing in the context of cardiac myxomas are extremely rare mixed tumours, with just few cases reported in literature.

\section{Case presentation}

A previously healthy 44 years-old female patient presented to our Hospital from an outpatient cardiology clinic with an echocardiographic finding of a floating mass within the left atrium.

She was symptomatic for a few months for asthenia, dyspnoea and dizziness She denied lypothymia or syncope and any history of drug/alcohol abuse or recent travels.

Her family history was negative for cardiovascular/neoplastic diseases.

The patient was in good clinical conditions, NYHA class I and CCS 0. Cardiac auscultation revealed a classical diastolic "tumour blop", not accompanied by any other significant murmur.

An urgent transthoracic echocardiogram with 3D digital reconstruction of the images was performed and confirmed the primary diagnosis (Fig. 1). The mass originated from ovalis fossa on the left side of the interatrial septum.

Maximum diameter was $3.5 \times 3 \mathrm{~cm}$. The mass had a lobulated and polypoid architecture and a narrow implantation stalk, appearing unstable, and prolapsed across the orifice of the mitral valve during diastole.

To complete the diagnostic framework, a cardiac, lung and brain CT scan (Fig 2) were performed, without any pathological finding and recent cardio-embolic events were also excluded.

The patient was then scheduled for surgery.

The operation was performed trough a left atriotomy. The tumour presented as a pale pink, grape-like, semitransparent mass. It had a particularly gelatinous and friable consistency with a high risk of fragmentation during surgical manipulation. Due to these atypical characteristics, we suspected the malignant nature of the neoplasm.

In order to perform a cautious removal of the mass, we started resecting it $2 \mathrm{~mm}$ from the implant base using a \#11 scalpel blade to reduce the risk of tumour fragmentation.

The next step was to perform a radical full-thickness resection of the implant base, located on the atrial septum, leaving a safety margin of 5 millimetres. Repeated and extended washing of the left chambers of the heart followed to reduce the risk of remaining tumour fragments embolization.

The redundant interatrial septum, though largely resected, was closed by a direct suture.

No complications occurred in the postoperative period, and the patient was discharged on the sixth postoperative day to a rehabilitation facility.

At gross examination, surgical specimens included: a lesion with dimensions of $3,5 \times 3 \mathrm{~cm}$ pedunculated, translucid and with a villous surface, focally covered by fibrinous exudate; a 1,5 cm implantation stalk and a fragment of interatrial septum.

Histological analysis showed that the lesion was made up of myxoid matrix containing thin vessels and scattered stellate cells without mitotic activity and cytologic atypias. Interestingly, the fibrinous layer focally covering the lesion contained few dense aggregates consisting of large, blastic lymphoid cells, with clear-cut atypical features (Fig.3).

At immunohistochemical staining, the stellate cells embedded in the myxoid matrix were positive for CD34, and negative for cytokeratins AE1/AE3, CD31 and CD45/LCA, and with a very low $(<2 \%)$ Ki67 proliferation rate. Such findings were consistent with cardiac myxoma.

Further immunohistochemical evaluation showed a B-cell phenotype (positive for CD20, PAX5, CD79A) of the atypical, blastic lymphoid cells, along with partial positivity for BCL6, IRF4, BCL2, CD30 and C-MYC 
( $<40 \%$ of cells), negativity for CD10, CD5, CD15, ALKc and HHV8, and a very high Ki67 proliferation index (> 80\%). In situ hybridization for Epstein-Barr virus (EBV/EBER) was diffusely positive (Fig. 3).

Histologic features and incidental finding were all consistent with an EBV-positive fibrin-associated large B-cell lymphoma, arising within a cardiac myxoma.

The implantation stalk was focally involved by myxoma, but free of lymphoma, suggesting a complete resection of the lesion.

Total body CT scan and 18-FDG Positron Emission Tomography excluded distant metastases. Oncologic consultation did not give any indication for adjuvant chemotherapy or radiotherapy.

\section{Discussion}

Myxoma is the most common type of tumour among all primary cardiac neoplasms [1]. Usually, they originate from the oval fossa with a growth directed towards the left atrial cavity [3]. Common symptoms are related to embolic events due to myxoma fragments embolization and syncope episodes due to diastolic obstruction of the mitral valve [1].

Cardiac lymphomas are instead rare, amounting to only $0.6 \%$ of all cardiac tumours. Although several subtypes of lymphomas may arise in the heart, the most common is diffuse large B-cell lymphoma not otherwise specified (DLBCL-NOS), usually associated with an aggressive biologic behaviour [5-7].

On the other side, the most frequent lymphoproliferative disease associated with cardiac myxoma is fibrinassociated diffuse large B-cell lymphoma (FA-DLBCL), with 16 cases reported so far [8].

FA-DLBCL is a recently recognized entity [9], included within the spectrum of diffuse large B-cell lymphomas associated with chronic inflammation and has highly distinctive features: it arises in fibrinous material covering or contained in sites of chronic inflammation (most commonly within the cardio-vascular system), neither forming a mass nor producing specific symptoms $[9,10]$. Typically, the diagnosis is incidental, during histologic examination.

FA-DLBCL is invariably EBV-positive.

It is therefore likely that most of the previous reported cases of lymphomas arising in association to cardiac myxomas would be re-classified into FA-DLBCL according to the current WHO classification, due to the concomitant [9] positivity for EBV [10-18] and for the typical localization within the fibrinous material covering the myxoma $[19,20]$.

Most importantly, despite aggressive histologic features (large cell morphology, high proliferation index), FA-DLBCL is a localized disease with an indolent behaviour and a favourable outcome even with surgical excision alone. The rare event of relapse and the associated risk of local invasion $[3,9,21]$, however, reinforces the need for a complete surgical excision.

Our case report suggests that cardiac surgeons must be aware that even apparently benign cardiac masses can conceal malignant lesions, adopting an attitude of presumption of "malignity until proven otherwise", that should prompt always an accurate and radical excision of the mass.

The recognition of a macroscopic unusual appearance of the lesion is of paramount importance, as

all the reported cases of lymphoid proliferation arose within a cardiac myxoma showed a partial or global gelatinous aspect of the neoplasm (especially in its peripheral areas) (Tab 1).

The rarity of this disorder is an obstacle to prospective studies. Endocavitary masses with the peculiar macroscopic characteristics we have described could indicate a high probability of lymphocytic infiltration in the context of myxomatous masses. In this case, a specific, integrated diagnostic and therapeutic pathway should be followed, including: wide and radical resection and possibly a bone marrow specimen (easily collectable during surgery from the sternal bone), to ensure a fast staging if the lesion would be proven malignant. 


\begin{abstract}
Abbreviations
EBV: Epstein-Barr virus.

DLBCL-NOS: large B-cell lymphoma not otherwise specified.
\end{abstract}

FA-DLBCL: fibrin-associated diffuse large B-cell lymphoma.

\title{
Acknowledgements
}

Not applicable.

\section{Authors' contributions}

SP, GM: Case design \& writing.

SF, FM, SP, GM: Editing of manuscript.

SP, GM, GP: Participated in its design.

All authors read and approved the final manuscript.

\section{Funding}

Not applicable.

\section{Availability of data and materials}

Data sharing not applicable to this article as no datasets were generated or analysed during the current study.

\section{Ethics approval and consent to participate}

Not applicable.

\section{Consent for publication}

Obtained.

\section{Competing interests}

The authors declare that they have no competing interests.

\section{Author details}

1 Department of Cardiac Surgery, Centro Cardiologico Monzino, via Carlo Parea 4- 20138 IRCCS, Milan, Italy.

2 Department of Cardiovascular Sciences and Community Health, University of Milan, Italy.

3 Division of Diagnostic Haematopathology, European Institute of Oncology, IRCCS, Via Ripamonti 435, 20141 Milan, Italy.

4 Division of Pathology, European Institute of Oncology IRCCS, Via Ripamonti 435, 20141 Milan, Italy

\section{Reference}

1. Bogaert J, Dymarkovski S, Taylor A, Muthurangu V. Clinical Cardiac MRI. 2nd edition. Berlin, Springer;2012.

2. Miguel CE, Bestetti RB. Primary cardiac lymphoma. Int J Cardiol 2011;149(3):358-63.

3. Pineda AM, Mihos CG, Nascimento FO, Santana O, Lamelas J, Beohar N. Coronary Embolization from a Left Atrial Myxoma Containing Malignant Lymphoma Cells. Tex Heart Inst J 2015;42(6):565-8 
4. Patel J, Sheppard M.N., Pathological study of primary cardiac and pericardial tumours in a specialist UK Centre: surgical and autopsy series, Cardiovasc Pathol. 19 (2010) 343-352.

5. Lam KY, Dickens P, Chan AC. Tumors of the heart. A 20-year experience with a review of 12,485 consecutive autopsies. Arch Pathol Lab Med. 1993;117:1027-1031.

6. Bruce CJ. Cardiac tumours: Diagnosis and management. Heart. 2011;97:151-160. doi: 10.1136/hrt.2009.186320.

7. Petrich A, Cho SI, Billett H. Primary cardiac lymphoma: An analysis of presentation, treatment and outcome patterns. Cancer. 2011;117:581-589. doi: 10.1002/cncr.25444

8. Zanelli M, Zizzo M, Montanaro M, Gomes V, Martino G, De Marco L, Fraternali Orcioni G, Martelli MP, Ascani S, BMC Cancer. 2019 Sep 13;19(1):916. doi: 10.1186/s12885-019-6123-1. Fibrin-associated large B-cell lymphoma: first case report within a cerebral artery aneurysm and literature review.

9. Boyer DF, McKelvie PA, de Leval L, Edlefsen KL, Ko YH, Aberman ZA, Kovach AE, Masih A, Nishino HT, Weiss LM, Meeker AK, Nardi V, Palisoc M, Shao L, Pittaluga S, Ferry JA, Harris NL, Fibrinassociated EBV-positive Large B-Cell Lymphoma: An Indolent Neoplasm With Features Distinct From Diffuse Large B-Cell Lymphoma Associated With Chronic Inflammation. Sohani AR.Am J Surg Pathol. 2017 Mar;41(3):299-312. doi: 10.1097/PAS.0000000000000775.

10. Yan J, Luo D, Zhang F et al, Diffuse large B cell lymphoma associated with chronic inflammation arising within atrial myxoma: aggressive histological features but indolent clinical behaviour, Histopathology 2017.

11. Loong F, Chan AC, Ho BC, Chau YP, Lee HY, Cheuk W, et al. Diffuse large B-cell lymphoma associated with chronic inflammation as an incidental finding and new clinical scenarios. Mod Pathol 2010;23(4):493-501.

12. Svec A, Rangaiah M, GilesM, Jaksa R, McAulay KA. EBV+ diffuse large B-cell lymphoma arising within atrial myxoma. An example of a distinct primary cardiac EBV+ DLBCL of immunocompetent patients. Pathol Res Pract 2012;208(3):172-6.

13. Bartoloni G, Pucci A, Giorlandino A, Berretta M, Mignosa C, Italia F, et al. Incidental Epstein-Barr virus associated atypical lymphoid proliferation arising in a left atrial myxoma: a case of long survival without any postsurgical treatment and review of the literature. Cardiovasc Pathol 2013;22(3):e5-10.

14. Aguilar C, Beltran B, Quinones P, Carbajal T, Vilcapaza J, Yabar A, et al. Large B-cell lymphoma arising in cardiac myxoma or intracardiac fibrinous mass: a localized lymphoma usually associated with Epstein-Barr virus? Cardiovasc Pathol 2015; 24(1):60-4.

15. Tapan U, Pestana JB, Lee JC, Lerner A. Epstein-Barr virus-associated diffuse large Bcell lymphoma arising in atrial myxoma: a proposal for a modified therapeutic approach. Leuk Lymphoma 2015;56(2):505-7.

16. Pineda AM,Mihos CG, Nascimento FO, Santana O, Lamelas J, Beohar N. Coronary Embolization from a Left Atrial Myxoma Containing Malignant Lymphoma Cells. Tex Heart Inst J 2015;42(6):565-8.

17. Liu X, Liu P, Li J. EBV+diffuse large B-cell lymphoma arising within atrialmyxoma in Chinese immunocompetent patient. Int J Clin Exp Pathol 2015;8(2):2159-64.

18. Alexandr Svec, ${ }^{*}$, Madhusudan Rangaiahb, Montserrat Gilesa, Radek Jaksac, Karen A. McAulayd $\mathrm{EBV}+$ diffuse large B-cell lymphoma arising within atrial myxoma. An example of a distinct primary cardiac EBV+ DLBCL of immunocompetent patients

19. Bagwan IN, Desai S, Wotherspoon A, Sheppard MN. Unusual presentation of primary cardiac lymphoma. Interact Cardiovasc Thorac Surg . 2009;9(1):127-129. doi:10.1510/icvts.2009.204628

20. Dimitrova KR, Hoffman DM, Geller CM, Thiagarjah P, Master J, Berger M, et al. Malignant B-cell lymphoma arising in a large, left atrial myxoma. Ann Thorac Surg 2010;89(2):626-9.

21. Kameda K, Shono T, Takagishi S et al, Epstein-Barr virus-positive diffuse large B-cell primary central nervous system lymphoma associated with organized chronic subdural hematoma: a case report and review of the literature, Pathol Int 2015.

22. Boyer, D. F., McKelvie, P. A., De Leval, L., Edlefsen, K. L., Ko, Y. H., Aberman, Z. A., Kovach, A. E., Masih, A., Nishino, H. T., Weiss, L. M., Meeker, A. K., Nardi, V., Palisoc, M., Shao, L., Pittaluga, S., Ferry, J. A., Harris, N. L., \& Sohani, A. R. (2017). Fibrin-associated EBV-positive 
Large B-Cell Lymphoma: An Indolent Neoplasm with Features Distinct from Diffuse Large B-Cell Lymphoma Associated with Chronic Inflammation. American Journal of Surgical Pathology , 41 (3), 299-312.

23. Yan J, Luo D, Zhang F, He J, Yao S, Luo X, Hu F, Chen Y, Fu L, Xu J, Liu Y. Diffuse large B-cell lymphoma associated with chronic inflammation arising within atrial myxoma: aggressive histological but indolent clinical behaviour. Histopathology. 2017;71:951-9.

\section{Table of figure:}

Fig $1: 2 \mathrm{D}$ transthorachic echocardiography images and 3D reconstruction of the left atrial mass.

Fig 2: CT based 3D virtual reconstruction of the mass performed using MIMICS software showing the extremely irregular borders and a narrow implantation stalk on the fossa ovalis.

Fig.3 : A,B,C: morphologic features of the lesion. Whole-mount section of myxoma, with villous surface and a superficial fibrinous cap (arrows) containing lymphoid aggregates (A, haematoxilin-eosin). The myxoma is made up of translucent loose matrix, containing scattered stellate cells (asterisk). The lymphoid cells embedded in fibrinous material (arrowhead) are large-sized and atypical (B, C, inset, haematoxilin-eosin). D, E, F: : Immunophenotypic features of fibrin-associated diffuse large B-cell lymphoma. The atypical lymphoid cells have a B-cell phenotype, being positive for CD20 (A) and PAX5 (B), are diffusely positive for EBV/EBER (C) and have a high Ki67 proliferation index (D), in contrast to the myxoma cells (D, upper half) which are almost completely negative for Ki67.

\section{Hosted file}

Table 1.pdf available at https://authorea.com/users/392026/articles/506044-a-malignantlymphoma-growing-inside-a-cardiac-mixoma-a-case-report 

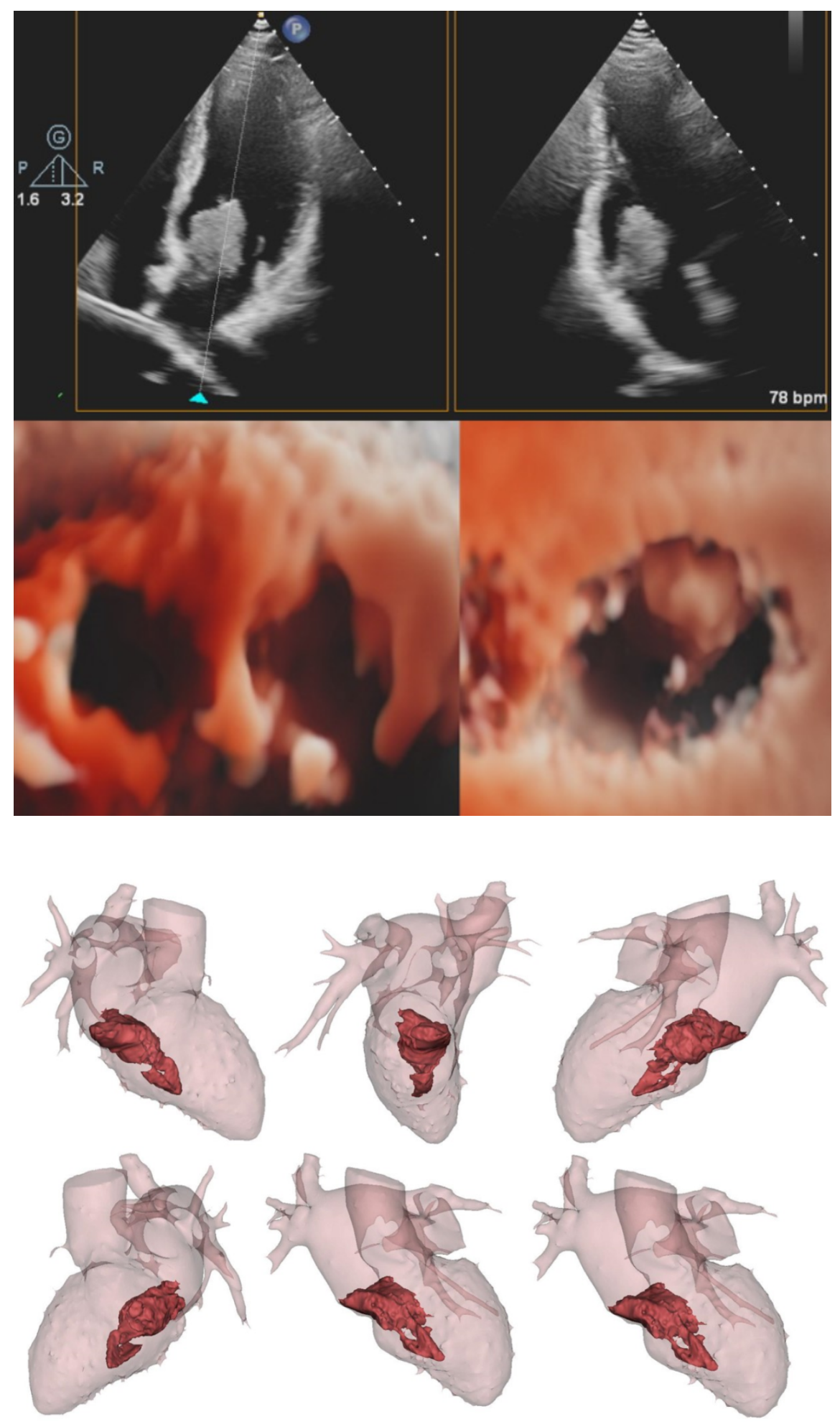


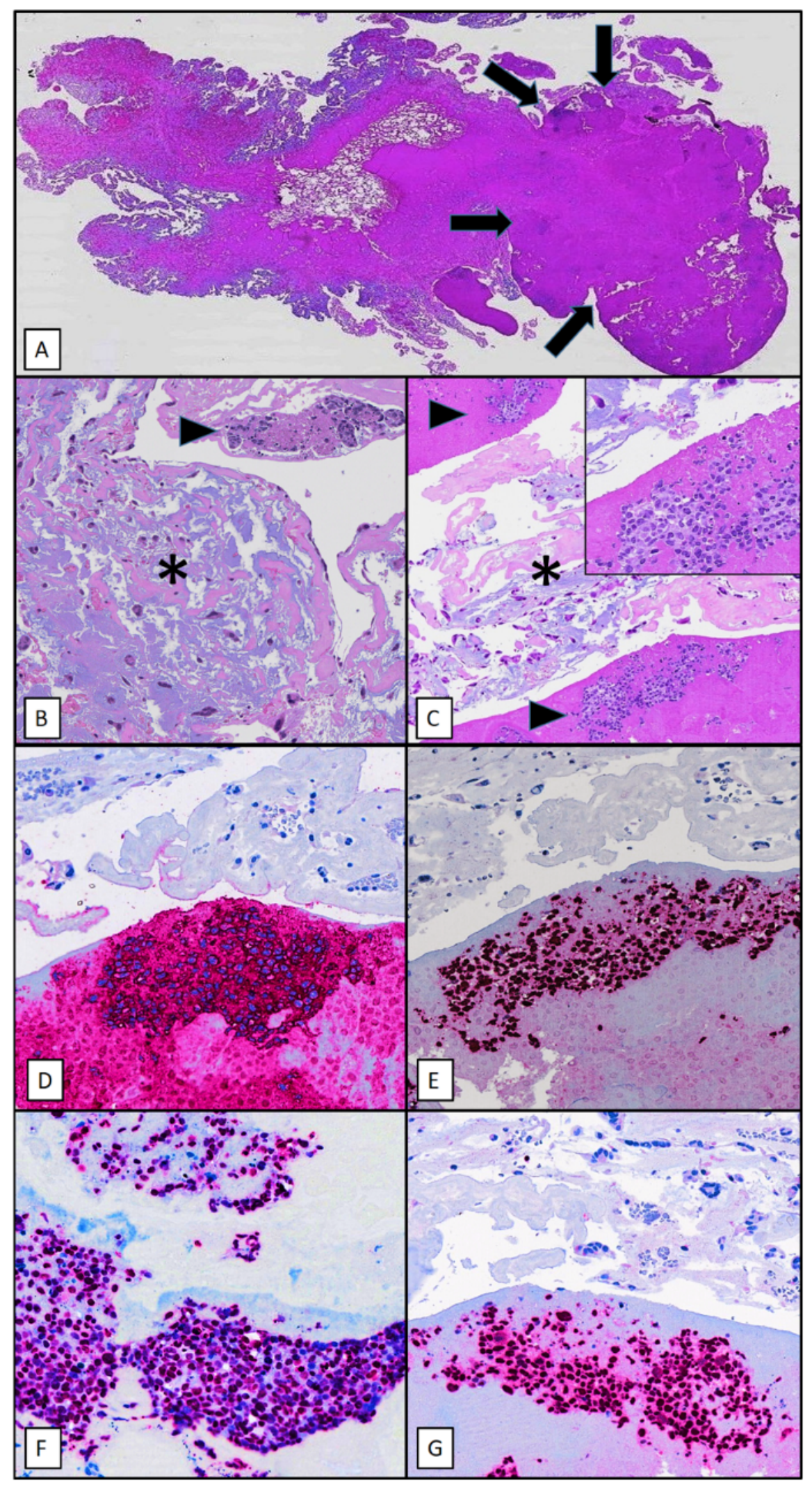

